\title{
Geopolymer: A Review of Structure, Applications and Properties of Fiber Reinforced Composites
}

\author{
Ellen Guimarães Oliveira Grance ${ }^{1}$, Maria das Dores Macedo Paiva ${ }^{2}$, Fernando Gomes de Souza Junior ${ }^{1,2 *}$ and \\ Romildo Dias Toledo Filho \\ ${ }^{1}$ Instituto de Macromoléculas Professora Eloisa Mano, Brazil \\ ${ }^{2}$ Programa de Engenharia Civil, Brazil \\ *Corresponding author: Fernando Gomes de Souza Juniour, instituto de Macromoleculas Professora Eloisa Mano, Brazil
}

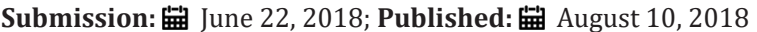

\begin{abstract}
Geopolymers are a new class of high performance materials able to replace traditional Portland cement due to its excellent mechanical properties, high initial resistance and durability. The raw material used for the production of geopolymers generally consists of industrial wastes such as fly ash and met kaolin, both rich in silica and alumina. Thus, geopolymers are an economically viable alternative for minimizing environmental impact by carbon sequestration. Although extremely resistant, their mechanical properties can be improved by the insertion of reinforcing agents. Among them, the fibers improve several properties such as tensile strength and toughness; besides allow controlling the cracking mechanism and the ductility of the geopolymer composites. Among the fibers used as geopolymer reinforcement the metallic, inorganic, organic and natural fibers should be highlighted. Each of these reinforcement materials influences positively the mechanical properties of the geopolymer composite, thus favoring a wide range of applications, especially in civil construction. Therefore, the objective of this work was to study the influence of the addition of different fibers on the mechanical properties of geopolymer matrix composites.
\end{abstract}

Keywords: Geopolymers; Composites; Fibers; Mechanical properties

\section{Introduction}

In 1978 the Australian researcher Davidovits [1,2] named inorganic polymers based on aluminosilicates as geopolymer. Geopolymers are materials formed via the polymerization reaction between the precursor aluminosilicates in alkaline solution. Its structure contains $\mathrm{SiO}_{4}$ and $\mathrm{AlO}_{4}$ ordered tetrahedral throughout the chain. Among the cavities are the alkaline ions that counterbalance the electric charges. Among the applications of the geopolymers, it is worth mentioning their use as binders, thus constituting an excellent substitution alternative to the traditional Portland cements, since they have superior mechanical properties, flammability, chemical resistance and durability. In addition, geopolymers can be prepared at room temperature with 80 to $90 \%$ reduction of $\mathrm{CO}_{2}$ emissions compared to Portland cements [3].

Geopolymers are produced from a range of industrial byproducts such as fly ash (produced by the burning of coal in thermoelectric plants), rice husk ash, sugarcane biogases ash, blast furnace slag, met kaolin and other mineral wastes containing sufficient amounts of alumina and silica. Despite the abundance of raw materials, the industries did not fully adhere to the geopolymers due to the high degree of variability in relation to environmental and financial costs [4].
The cost of the geopolymer is strongly related to the origin of the raw material, the source of energy and the means of transport. Depending on these three variables geopolymers may become more expensive than Portland cements [4]. Australia has abundant fly ash produced by coal-fired power stations. However, in Brazil, in addition to mineral reserves rich in aluminosilicates, there are many industrial processes that generate the fly ash that can be used to exploit this echnology [5].

In spite of these variables, geopolymers have been aware of the interest of the industries due to their characteristics such as: low density $\left(700-1800 \mathrm{~kg} / \mathrm{m}^{3}\right)$, easy processing, low cure temperature and being environmentally friendly. However, nonreinforced geopolymers can suffer a fragile fracture, which limits its application in the civil construction area. Thus, in recent years, several studies have been carried out on composites of fiberreinforced geopolymers, as the fibers improve the strength and toughness of the geopolymeric composites [6].

In general, fibers and in particular polypropylene (PP) fibers are widely used as reinforcement for concrete (mixing of water, aggregates and geopolymer cement) because they reduce material shrinkage and improve the breaking strength of the single concrete. 
The fibers can be divided into low and high modulus. Low modulus fibers such as nylon, polypropylene and polyethylene mainly improve energy absorbing and impact resistance characteristics, since high modulus fibers such as steel, glass and asbestos improve strength and hardness of composites [4].

Another characteristic of the fibers that influence the properties of the composites is its size. Short fibers can become agglomerated and generate void spaces compromising the quality of the composite. Long fibers present better results since the transfer of stresses from the matrix to the fibers is more efficient. The fibers can also be natural or synthetic, natural fibers have unique advantages as an environmentally friendly alternative because they have low density, lower cost, toxicity, and ease of processing [7].

\section{Literature Review}

\section{Geopolymers}

The geopolymers make up a family of materials based on polymerized oxide-aluminosilicates (pozzolans). The process of obtaining the geopolymers consists in the dissolution of $\mathrm{Al}$ and $\mathrm{Si}$ in alkaline medium. The alkaline solution is composed of soluble cations. Usually sodium or potassium based, the most commonly used being sodium hydroxide $(\mathrm{NaOH})$ or potassium hydroxide $(\mathrm{KOH})$, often combined with sodium or potassium silicate. After reaction of polycondensation, a gel of three-dimensional structure is formed that later hardens forming a mechanically resistant matrix [8].

Geopolymers are also called polysialates, terminology adopted as an abbreviation for poly (silico-aluminates) [9-11]. Its structure depends on the $\mathrm{Si} / \mathrm{Al}$ ratio as described below: poly(sialate) $-\mathrm{Si}$ O-Al-O- (Si:Al=1), poly(sialate-siloxo) -Si-O-Al-O-Si-O- (Si:Al=2), poly(sialate-disiloxo) -Si-O-Al-O-Si-O-Si-O- $(\mathrm{Si}: \mathrm{Al}=3)$, poly(sialatemultisiloxo) (Si:Al $>>3$ ). The following formula describes the different structures: $\mathrm{Mn}\left[-\left(\mathrm{Si}-\mathrm{O}_{2}\right)_{\mathrm{z}}-\mathrm{Al}-\mathrm{O}\right]_{\mathrm{n}} \cdot \mathrm{wH}_{2} \mathrm{O}$ [12-14]. Where "M" is a cation (alkaline element), " $\mathrm{n}$ " is the degree of polymerization, the symbol (-) indicates the presence of a bond, " $z$ " is 1,2 or 3 and "w" is the degree of hydration [15].

The geopolymer structure resembles the zeolite structure [16-18]. The zeolites are hydrated aluminosilicates of alkali or alkaline earth metals (such as $\mathrm{Na}, \mathrm{K}, \mathrm{Mg}$ and $\mathrm{Ca}$ ) composed of three-dimensional and porous crystalline structures, formed by tetrahedra of the type $\mathrm{SiO}_{4}$ and $\mathrm{AlO}_{4}$ joined in the vertex by atoms of oxygen [19].

Although the geopolymers have the same chemical constitution as the zeolites, they have a significant difference: the zeolites are highly crystalline whereas the geopolymers are amorphous or semi-crystalline [15]. However, during the geopolymerization process zeolites are formed, being the hydroxysodalite $\left(\mathrm{Na}_{6} \mathrm{Al}_{6} \mathrm{Si}_{6} \mathrm{O}_{24} 8 \mathrm{H}_{2} \mathrm{O}\right)$ an example of a type of zeolite formed by the activation of metakaolin with $\mathrm{NaOH}$. Thermodynamically, the zeolite $\mathrm{A}-\mathrm{Na}_{12} \mathrm{Al}_{12} \mathrm{Si}_{12} \mathrm{O}_{48} \cdot 27 \mathrm{H}_{2} \mathrm{O}$ is a metastable phase and thus tends to transform into hydroxysodalite over time [20].

According to Freitas [21] the composition and synthesis of geopolymers are determining factors for the hardening and curing process, as well as for the final mechanical behavior. The geopolymers harden at room temperature and have the high compressive strength (about $70 \%$ at 4 hours cure), a hardness of about 200HB (Hardness Brinell) and are stable at temperatures above $1400^{\circ} \mathrm{C}$. However, they are brittle and require fibers to inhibit the formation of microcracks during geopolymerization.

\section{Application of geopolymers in civil construction}

Differentiated properties that allow specific applications can be achieved as a function of the $\mathrm{Si} / \mathrm{Al}$ atomic ratio [22-29]. As the $\mathrm{Si} / \mathrm{Al}$ ratio increases, increases the polymeric character suitable for applications where materials with high fire resistance are required. In the case of binder materials, applied in civil construction, these are predominantly amorphous and usually based on polysiloxosialate [30]. Geopolymers have a great potential application due to the high resistance to initial compression, fast stiffness, and low volumetric variation. They can be used in precast concrete industries, as well as re-plating in airport runways or roads, in the manufacture of mechanical blocks and the cementing of oil wells [31-37].

The optimization of the study of the properties of the geopolymer slides concerning the activator concentration, solid/ liquid dosage in the mixture, time and curing temperature allowed the use of the geopolymer slurries for the manufacture of products such as concrete mortars, geopolymer foam, solid blocks [38]. Hung [39] studied carbon fiber-reinforced geopolymer composites with potential application in environments where they require high resistance to burning, such as in-cabin interiors and other aircraft components. The results were propitious for burning resistance, UV resistance, and toxicity.

\section{Vegetable Fibers}

Among the numerous fibers available for the reinforcement of geopolymer composites, such as of vegetable origin deserve special mention. This is mainly because that they promote adequate reinforcement, associated with low cost and from renewable and abundant sources. Besides that, Brazil is a country with high biomass and great territorial extension that allows exploring the use of these fibers in geopolymer matrix composites [40-45].

Vegetable fibers can be classified according to their origin as leaf (sisal and curauá), seed (cotton), fruit (coconut) and stem (jute, flax, ramie, and hemp) [46]. Vegetable fibers, other than cotton, consist of cellulose, hemicellulose, lignin and other organic components. The main component of vegetable fibers is cellulose. The cellulose chains form micro fibrils which are joined together by intermediate lamella, made up of hemi cellulose and lignin [47-56]. Cellulose is a semi crystalline polysaccharide and possesses large amounts of hydroxyl groups. It provides fiber strength, rigidity, and stability [48,57-59]. Hemi cellulose is entirely amorphous and consists of hydroxyl and acetyl groups. It acts as a binding agent between cellulose and lignin [56]. Lignin is an amorphous polymer of complex structure and aromatic nature formed by phenyl propanoid units and is responsible for the mechanical resistance of plants [60]. 
The hydrophilic nature of the cellulosic fiber is responsible for the weak resistance and weak interfacial bond when these fibers are used as reinforcement in hydrophobic matrices. The presence of the pendant hydroxyl group and polar groups leads to high moisture absorption through intermolecular hydrogen bonds, which leads to dimensional instability of the fiber and poor mechanical performance of the composite [61-63].

\section{Surface treatment of vegetable fibers}

A significant problem in the use of plant fibers is their durability and compatibility between the fiber and the geopolymer matrix. The alkaline matrix medium tends to weaken most of the vegetable fibers which are composed of various yarns of individual filaments which can be separated from one another. As consequence, occurs the loss of the mechanical properties of the cementations composite [64-67].One of the ways of improving the durability of the fibers is by reducing the alkalinity of the matrix by modifying its composition or by modifying the surface fibers which promote the increase of fiber-matrix adhesion [68-71]. However, lower alkalinity is not recommended, since this is the polymerization activation system. Therefore, the preferred route must be to modify the plant fibers, increasing their resistance to alkaline attack and improving their compatibility with the matrix. This increase in fiber-matrix interaction is significant because the interfacial region is primary to the transfer of tensions from the matrix to the reinforcement Therefore, an inadequate adhesion between these phases may cause the initiation of failures thus compromising the performance of the composite $[72,73]$.

To solve the problems of degradation and low interfacial adhesion, physical and chemical methods can be used to optimize cohesive strength at the fiber interface. These treatments modify the fiber surface through reactive functional groups capable of binding to the reactive groups of the matrix. Thus, these treatments generate hydrophobic fibers with a greater roughness of the fiber surface and greater affinity with the matrix [74-77]. However, prior knowledge of the chemical composition and morphology of plant fibers is essential to understand how fibers react to the attack of chemical agents [78]. Depending on the type of lignocellulosic fiber, the lignin can be entirely dissolved by the alkalinity of the geopolymer matrix resulting in a decrease in tensile strength $[79,80]$.

Since natural fibers have hydroxyl groups of cellulose and lignin, they are subject to chemical modification. Among the various treatments of the fibers are alkali treatment, hornification (wetting and drying cycles in the fibers), isocyanate, acrylation, permanganate, acetylation, methane, cold plasma, silane, peroxides, among others [81-83]. Treatment with an alkaline solution $(\mathrm{NaOH})$ also called mercerization, is widely used in plant fibers. This treatment can increase the roughness of the fiber surface, as it separates the fiber bundles by breaking the hydrogen bonds and removing the components of the cell wall. Thus, the wet ability (degree of contact of the interface surfaces) of the mercerized fibers increases by improving the cohesive force in the interfacial region $[84,85]$.

Surface modification of the jute fibers with chemical treatments is used to partially remove amorphous components such as hemi cellulose and lignin to obtain as much cellulose as possible with high levels of crystalline. The removal of the amorphous components allows a better packaging of the cellulose chains thus increasing the crystallinity, besides promoting the reduction of the diameter and density of the fibers [86,87]. The higher the cellulose contents in the fiber the higher the mechanical properties and the resistance to thermal degradation [88].

Ray et al. [89] evaluated the influence of alkali treatment on jute fibers. They observed a reduction of fibers, lower hemi cellulose content and greater crystalline after treatment. The authors used $5 \%$ sodium hydroxide solution for immersion of the fibers for 2,4,6 and 8 hours. Crystalline increased $23.4 \%$ over untreated fibers. The flexural modulus of the fibers increased by 12, 68 and 79\% when exposed at 4, 6 and 8 hours, respectively, and the tensile strength increased $46 \%$ after 6 hours of immersion in alkaline solution.

Ferreira et al. [90] studied the effect of the hornification on the chemical and mechanical behavior of curauá, jute and sisal fibers. About 5 and 10 cycles of wetting and drying were applied to the fibers. The change in the cellulose crystalline and the possible bonds created between different polymer chains in the micro fibrils resulted in an increase in tensile strength and the number of cycles does not promote damage in curaua and jute structure. The hornification treatment promoted a higher fiber-matrix bond, also improving the frictional mechanism.

The combined alkali and polymer treatment increase the workability yield mortar. The use of carboxylated styrene butadiene polymer latex promotes a fiber surface that is hydrophobic and acts as a bridge between fiber and the cementitious matrices, strengthening the interfacial bonding between them [91]. According to Chakraborty et al. [92] an optimal polymer content in emulsion $(0.0513 \%)$ increased the compressive strength, modulus of rupture and flexural toughness, 25\%, 28\%, 387\% respectively as compared to control mortar without any jute reinforcement [18].

Fidelis et al. [93] showed that pullout tests with coated fabrics formed a stronger bond than did the uncoated. For Portland cement matrix the maximum fiber pullout force decreased up to $85 \%$ after six months of accelerated aging. Whereas in metakaolin matrix the degradation process was retarded substantially. Therefore, polymer coatings improved the bond between fiber and matrix and reduce fiber degradation. Santos et al. [94] submitted jute fibers to one cycle of soaking and drying in an alkaline hornification treatment using calcium hydroxide $\left(\mathrm{Ca}(\mathrm{OH})_{23} 0.7 \%\right.$ w/v They observed that even with only one cycle of alkaline hornification was very efficient to remove partially the lignin and hemicelluloses from the jute fibers. In the fiber morphology, it was possible to observe an increase in the thickness of the secondary fiber wall and reduction of the lumen. The mechanical resistance increased by $70 \%$ in the 
max load, $176 \%$ in the tensile strength, $133 \%$ in the strain and $9 \%$ to Young's modulus.

\section{Geopolymer matrix composites reinforced with natural fibers}

Geopolymer composites have become a promising ecological alternative for traditional cementitious materials. They are profitable, environmentally friendly and their production involves a relatively small amount of energy. They also have excellent compressive strength, durability, and good thermal properties. The addition of fibers to geopolymer composites reduces the propagation of micro cracks and inhibits brittle behavior by increasing ductility [95].

Among the fiber reinforcements most used in geopolymers are inorganic fibers such as carbon and glass fibers. However, natural fibers have attracted attention because they are renewable materials, low density and low cost of obtaining [95]. The incorporation of metallic fibers increases the flexural strength since the non-metallic fibers control the contraction of the matrix due to the high contact surface [96]. The characteristics of the fibers depend on many factors such as fiber size, fiber type, elastic properties, aspect ratio (ratio of length to diameter-L/D) and fiber volume fraction. Each type of fiber can be useful for some specific function [97]. Several studies on the effect of different fibers on the geopolymer matrix will be presented below. Vegetable fibers have some advantages over synthetic fibers such as lower cost, lower density, biodegradable, renewable and abundant. These characteristics make the vegetable fibers attractive to the industries allowing their use as a reinforcing agent in geopolymers [95].

Correia et al. [98] studied geopolymer matrix composites based on metakaolin reinforced with sisal fibers (Agave sisalana) and pineapple leaf fibers (Ananas comosus). The authors used for both fibers $3 \%$ by volume and $25 \mathrm{~mm}$ of length in the composites. After addition of the fibers in the geopolymer slurry, the material was cured at $55^{\circ} \mathrm{C}$ for 24 hours. The mechanical properties tests showed that the composite reinforced with pineapple fibers presented resistance values (compression, traction, and impact) below the composites reinforced with sisal fibers, but above the pure geopolymer.

The authors Ribeiro et al. [5] produced geopolymer composites reinforced with bamboo fibers (Guadua Angustifolia). The geopolymer matrix was synthesized using metakaolin produced from kaolinite clay extracted from Amazonian soil. The bamboo fibers were treated with deionized water (immersion for 3 days) and sodium hydroxide $(\mathrm{NaOH})$ to improve fiber-matrix interfacial adhesion. The composites, in general, presented improved resistance when compared to the pure geopolymer. There was no significant difference in the flexural strength of the fibers treated with water and $\mathrm{NaOH}$. The results revealed that the bamboo fiber reinforced geopolymer composite is a potential building material, green and sustainable.
Geopolymer composites reinforced with short cotton fibers were prepared by Alomayri \& Low [99]. They observed a minimal improvement in the flexural strength of the reinforced composites concerning the pure geopolymer. The increase in the fiber content of cotton promoted the formation of agglomerations and void spaces causing a poor dispersion of the fibers in the matrix, which decreased interfacial fiber-matrix adhesion and, consequently, led to the reduction of the mechanical properties of the materials.

However, in another paper authors Alomayri et al. [100] used continuous cotton fibers containing $0 ; 3.6 ; 4,5 ; 6.2$ and $8.3 \%$ mass. Also, the authors tested different amounts of layers, equal to $0,5,10,20$ and 40 , respectively. It was found that continuous cotton fibers presented better properties than short cotton fibers because of their ability to effectively bind cracks in relation to their alignment in the direction of stress resulting in a greater transfer of interfacial tension in the composites. The composite containing 8.3\% continuous cotton fiber exhibited the highest flexural strength between the composites analyzed. The flexural strength of the composites increased from 8.2MPa to 31.7MPa compared to the pure geopolymer. This allowed concluding that the increase in cotton fiber content led to a considerable improvement in the flexural strength of the geopolymer composite.

As in the result of flexural strength, the increase of the amount of fiber present in the composites was proportional to the impact resistance. The strength of the pure geopolymer increased from 2.1 to $15.6 \mathrm{~kJ} / \mathrm{m}^{2}$ after the addition of $8.3 \%$ of cotton fibers to the geopolymer composites. This significant improvement in impact strength can be attributed to the use of the applied load on the surface of the geopolymer composites during sample preparation, which aimed to expel trapped air into the matrix, forcing the geopolymer to penetrate into voids and porous spaces. As a consequence, the cohesion between the fibers and the matrix was increased resulting in an increase in impact strength [100].

Dong et al. [32] used sorghum fibers to prepare geopolymer composites. In order to increase fiber-matrix interfacial adhesion, the sorghum bagasse fibers were treated in $2 \mathrm{M} \mathrm{NaOH}$ solution for 12 hours. The alkaline solution was chosen because of compatibility with the alkali environment of the geopolymer. The alkali treatment of the fibers gives rise to the fibrillation (separation in fibers of smaller diameter) promoting a better surface of contact with the matrix. The performance of the composites was improved with the increase of the fiber content, but the excess of fiber promoted drastically the reduction of the properties of the geopolymer composites.

The splitting tensile test showed brittle fracture of the pure geopolymer sample and ductile fracture of the reinforced geopolymer containing $1 \%$ by mass of sorghum. The rupture of the fibers during the loading process absorbs energy and thus improves the tenacity of the geopolymer paste [101]. Assaedi et al. [102] studied the mechanical and thermal properties of geopolymer 
composites based on fly ash reinforced with continuous flax fibers. The amounts used were $2.4 ; 3.0$ and $4.1 \%$ mass of flax fabric in several layers. All mechanical properties such as flexural strength, compression, fracture and hardness were improved by increasing the amount of flax fibers employed, showing superior properties to the geopolymer matrix.

The flexural strength increased from $4.5 \mathrm{MPa}$ of the pure geopolymer to $23 \mathrm{MPa}$ of the composite containing $4.1 \%$ of flax fiber. The increase in the content of flax fibers has led to a significant improvement in flexural strength and this can be explained by the number of reinforcement layers that controls the flexural strength [102]. This improvement can also be seen in the work of Alzeer \& Mackenzie [3] that observed the flexural strength increase from $6 \mathrm{MPa}$ of the pure geopolymer to $70 \mathrm{MPa}$ of the composite containing $10 \%$ vol. of flax fiber. The addition of $10 \%$ of flax fiber allowed the geopolymer to change its brittle fracture behavior to a high ductility behavior.

The thermogram of the flax fibers presented three stages of degradation. The first transition occurred at approximately 25 to $240{ }^{\circ} \mathrm{C}$ related to the elimination of water molecules. The largest mass loss occurred between 240 and $365^{\circ} \mathrm{C}$ related to the decomposition of cellulose [102]. This result is in agreement with those of Alzeer \& Mackenzie [3], according to which, the greatest mass loss of short flax fibers under airflow is in the range of 240 to $340{ }^{\circ} \mathrm{C}$. The final phase occurs above $365^{\circ} \mathrm{C}$ when the fibers begin to decompose.

The loss of mass of the pure geopolymer occurred in the range of 25 to $300{ }^{\circ} \mathrm{C}$ caused by the evaporation of physically absorbed water. Above $300^{\circ} \mathrm{C}$ the mass loss was related to the dehydroxylation of the chemically bound water. The composite presented a mass loss of $10.5 \%$ at $260{ }^{\circ} \mathrm{C}$ relative to the evaporation of physically absorbed water. Above $260^{\circ} \mathrm{C}$, the composite presented more mass loss related to the degradation of the fiber content present in the sample. This is related to the porosity of the geopolymer matrix that allowed oxygen to enter, thus promoting the degradation of the fibers at high temperatures. The composite presented a total mass loss of $15 \%$ at $300{ }^{\circ} \mathrm{C}$ indicating a greater degradation of the fibers inside the composite [102]. Thus, among the many fibers available for the reinforcement of geopolymeric composites, those of vegetable origin deserve special mention. This is mainly due to the fact that they promote adequate reinforcement, associated with low cost and high availability. In addition, Brazil is a country that has high biomass and great territorial extension that allows exploring the use of these fibers in geopolymer matrix composites [95].

\section{Conclusion}

The studies evaluated in the present work allow concluding that the addition of fibers as a reinforcement element improves the mechanical properties of the geopolymer composites in relation to the matrix without reinforcement. According to the works studied, the mechanical behavior of the geopolymer matrix composites is influenced by a series of characteristics of the fibers and also of the matrix such as: fiber content and type, length to diameter ratio (L/D) of fibers, dimension of the aggregates, origin and dosage of the raw material for matrix formulation and fiber-matrix interfacial adhesion.

The metallic, organic, inorganic and natural fibers each have a particular mechanical performance, specific for a particular type of application. A common feature of these fibers is that they all promoted a significant increase in the physical properties of the geopolymer. However, the reinforcement with natural fibers proved to be the most complex, since it involves the use of materials that present different physical properties, associated to a polydispersity of these properties, which requires pretreatment steps of these fibers. These treatments homogenize the fibers or even alter their surfaces, producing a better interface, which greatly improves the mechanical properties of the geopolymer composites. This continued improvement in the properties of vegetable fibers will allow for the preparation of more resistant and less carbon footprint geopolymer systems, which makes these systems of great interest for the production of large-scale artifacts.

\section{Acknowledgment}

The authors thank Conselho Nacional de Desenvolvimento Científico e Tecnológico, Coordenação de Aperfeiçoamento de Pessoal de Nível Superior (CAPES and CAPES-NANOBIOTEC), Financiadora de Estudos e Projetos (FINEP PRESAL Ref.1889/10), and Fundação Carlos Chagas Filho de Amparo à Pesquisa do Estado do Rio de Janeiro (FAPERJ) for the financial support and scholarships.

\section{References}

1. Davidovits J (1989) Geopolymers and geopolymeric materials. J Therm Anal 35(2): 429-441.

2. Davidovits J (1991) Geopolymers. J Therm Anal 37: 1633-1656.

3. Alzeer M, Mac Kenzie K (2013) Synthesis and mechanical properties of novel composites of inorganic polymers (geopolymers) with unidirectional natural flax fibres (phormium tenax). Appl Clay Sci 7576: 148-152.

4. Reed M, Lokuge W, Karunasena W (2014) Fibre-reinforced geopolymer concrete with ambient curing for in situ applications. J Mater Sci 49(12): 4297-4304.

5. Sá Ribeiro RA, Sá Ribeiro MG, Sankar K, Kriven WM (2016) Geopolymerbamboo composite-A novel sustainable construction material. Constr. Build Mater 123(1): 501-507.

6. Yan S, He P, Jia D, Yang Z, Duan X, et al. (2016) Effect of fiber content on the microstructure and mechanical properties of carbon fiber felt reinforced geopolymer composites. Ceram Int 42(6): 7837-7843.

7. Alomayri T, Shaikh FUA, Low IM (2013) Thermal and mechanical properties of cotton fabric-reinforced geopolymer composites. J Mater Sci 48(19): 6746-6752.

8. Khale D, Chaudhary R (2007) Mechanism of geopolymerization and factors influencing its development: a review. J Mater Sci 42(3): 729-746. 
9. Kriven WM (2010) Inorganic polysialates or "geopolymers." Am Ceram Soc Bull 89: 31-34.

10. Šesták J, Foller B (2012) Some aspects of composite inorganic polysialates. J Therm Anal Calorim 108(2): 511-517.

11. Barbosa VFF, MacKenzie KJD, Thaumaturgo C (2000) Synthesis and characterisation of materials based on inorganic polymers of alumina and silica: sodium polysialate polymers. Int J Inorg Mater 2(4): 309-317.

12. Thomas A, Tripathi RK, Yadu LK (2018) A laboratory investigation of soil stabilization using enzyme and alkali-activated ground granulated blastfurnace slag. Arab J Sci Eng, pp. 1-10.

13. Shi C, Qian J (2003) Increasing coal fly ash use in cement and concrete through chemical activation of reactivity of fly ash. Energy Sources 25(6): 617-628.

14. Yip CK, Deventer JSJ (2003) Microanalysis of calcium silicate hydrate ge formed within a geopolymeric binder. J Mater Sci 38(18): 3851-3860.

15. Verdolotti L, Iannace S, Lavorgna M, Lamanna R (2008) Geopolymerization reaction to consolidate incoherent pozzolanic soil. J Mater Sci 43(3): 865-873.

16. Lolli F, Manzano H, Provis JL, Bignozzi MC, Masoero E (2018) Atomistic simulations of geopolymer models: the impact of disorder on structure and mechanics. ACS Appl Mater Interfaces 10(26): 22809-22820.

17. Minelli M, Papa E, Medri V, Miccio F, Benito P, et al. (2018) Characterization of novel geopolymer-Zeolite composites as solid adsorbents for $\mathrm{CO}_{2}$ capture. Chem Eng J 341: 505-515.

18. Papa E, Medri V, Amari S, Manaud J, Benito P, et al. (2018) Zeolitegeopolymer composite materials: Production and characterization. Clean Prod 171: 76-84

19. Fungaro DA, Borrely SI (2012) Synthesis and characterization of zeolite from coal ashes modified by cationic surfactant. Cerâmica 58: 77-83.

20. Maia AAB, Saldanha E, Angélica RS, Souza CAG, Neves RF (2007) Utilização de rejeito de caulim da Amazônia na síntese da zeólita A. Cerâmica 53: 319-324.

21. Freitas, Belísio de AS (2008) Adição de geomanta e tecido não tecido de polipropileno em cimentos geopoliméricos de pega rápida.

22. Glid M, Sobrados I, Rhaiem HB, Sanz J, Amara ABH (2017) Alkaline activation of metakaolinite-silica mixtures: Role of dissolved silica concentration on the formation of geopolymers. Ceram Int 43(15): 12641-12650.

23. Lahoti M, Wong KK, Yang EH, Tan KH (2017) Effects of Si/Al molar ratio on strength endurance and volume stability of metakaolin geopolymers subject to elevated temperature. Ceram Int 44(5): 5726-5734.

24. Liew YM, Heah CY, Li L, Jaya NA, Abdullah MMAB, et al. (2017) Formation of one-part-mixing geopolymers and geopolymer ceramics from geopolymer powder. Constr Build Mater 156: 9-18.

25. Wan Q, Rao F, Song S, García RE, Estrella RM, et al. (2017) Geopolymerization reaction, microstructure and simulation of metakaolin-based geopolymers at extended $\mathrm{Si} / \mathrm{Al}$ ratios. Cem Concr Compos 79: 45-52.

26. Casarez CAR, Rea SPA, Enríquez AC, Higuera RC, Cervantes MP, et al. (2018) Influence of size reduction of fly ash particles by grinding on the chemical properties of geopolymers. Appl Sci 8(3): 365

27. Lee B, Kim G, Kim R, Cho B, Lee S, et al. (2017) Strength development properties of geopolymer paste and mortar with respect to amorphous $\mathrm{Si} / \mathrm{Al}$ ratio of fly ash. Constr Build Mater 151: 512-519.

28. Fasihnikoutalab MH, Pourakbar S, Ball RJ, Huat BK (2017) The effect of olivine content and curing time on the strength of treated soil in presence of potassium hydroxide. Int J Geosynth Ground Eng 3: 12.
29. Ye N, Chen Y, Yang J, Liang S, Hu Y, et al. (2017) Transformations of Na, $\mathrm{Al}$, $\mathrm{Si}$ and Fe species in red mud during synthesis of one-part geopolymers. Cem Concr Res 101: 123-130.

30. Noda C, Livi (2013) Desenvolvimento de pasta de geopolímeros a base de cinza volante e hidróxido de sódio.

31. Gunasekera C, Setunge S, Law DW (2017) Correlations between mechanical properties of low-calcium fly ash geopolymer concretes. J Mater Civ Eng 29(9).

32. Dong M, Feng W, Elchalakani M, Li GK, Karrech A ,et al. (2017) Development of a high strength geopolymer by novel solar curing. Ceram Int 43(14): 11233-11243.

33. Payakaniti P, Pinitsoontorn S, Thongbai P, Amornkitbamrung V, Chindaprasirt P (2017) Electrical conductivity and compressive strength of carbon fiber reinforced fly ash geopolymeric composites. Constr Build Mater 135: 164-176.

34. Aboshia AMA, Rahmat RA, Zain MFM, Ismail A (2017) Enhancing mortar strengths by ternary geopolymer binder of metakaolin, slag, and palm ash. Int J Build Pathol Adapt 35(5): 438-455.

35. Kumar KA, Partheeban P (2017) Experimental investigation on compressive strength of geopolymer concrete paver block. Int J Appl Eng Res 12(13): 3659-3664.

36. Lirer S, Liguori B, Capasso I, Flora A, Caputo D (2017) Mechanical and chemical properties of composite materials made of dredged sediments in a fly-ash based geopolymer. J Environ Manage 191: 1-7.

37. Yang C (2017) Prediction of the compressive strength from resonant frequency for low-calcium fly ash-based geopolymer concrete. UVicSpace, pp. 1-41

38. Singh B, Ishwarya G, Gupta M, Bhattacharyya SK (2015) Geopolymer concrete: A review of some recent developments. Constr Build Mater 85: 78-90.

39. Hung TD, Louda P, Kroisová D, Bortnovsky O, Xiem NT (2011) New generation of geopolymer composite for fire-resistance. Advances in Composite Materials-Analysis of Natural and Man-Made Materials, China, pp. 73-92.

40. Souza FG, Andréa Maria, Oliveira GE, Costa RM, Fernandes ER, et al. (2015) Conducting and magnetic mango fibers. Ind Crops Prod 68: $97-$ 104.

41. Ferreira SR, Da Silva AM, Souza FG, Filho RDT, Andrade SF (2014) Effect of polyaniline and $\mathrm{H}_{2} \mathrm{O}_{2}$ surface modification on the tensile behavior and chemical properties of coir fibers. J Biobased Mater Bioenergy 8(6): 578586.

42. Picciani PHS, Soares BG, Medeiros ES, Souza F, Wood DF, et al. (2009) Electrospinning of polyaniline/poly(lactic acid) ultrathin fibers: process and statistical modeling using a non gaussian approach. Macromol Theory Simul 18(9): 528-536

43. Souza FG, Pinto CJ, Garcia AF, Oliveira GE, Tavares B, et al. (2014) Modification of coconut fibers with polyaniline for manufacture of pressure-sensitive devices. Polym Eng Sci 54(12): 2887-2895.

44. Souza FG, Oliveira GE, Rodrigues CHM, Soares BG, Nele M, et al.(2009) Natural Brazilian amazonic (Curauá) fibers modified with polyaniline nanoparticles. Macromol Mater Eng 294(8): 484-491.

45. Elias E, Costa R, Marques F, Oliveira G, Guo Q, et al. (2015) Oil-spill cleanup: The influence of acetylated curaua fibers on the oil-removal capability of magnetic composites. J Appl Polym Sci 132(13): 4173241740.

46. Figueiredo NA, Olivier CN, Cordeiro RE, Oliveira HP (2017) Determination of mango ripening degree by electrical impedance spectroscopy. Comput. Electron Agric 143: 222-226. 
47. Fernandes EM, Pires RA, Mano JF, Reis RL (2013) Bionanocomposites from lignocellulosic resources: Properties, applications and future trends for their use in the biomedical field. Prog Polym Sci 38: 1415 1441

48. Li R, Fei J, Cai Y, Li Y, Feng J, et al. (2009) Cellulose whiskers extracted from mulberry: A novel biomass production. Carbohydr Polym 76(1): 94-99.

49. Moubashe M, Hafez SA, Fattah HA, Mohanram A (1982) Direct estimation of Cellulose, Hemicellulose and Lignin. J Agric Res 46: 1467-1476.

50. Brígida AIS, Calado VMA, Gonçalves LRB, Coelho MAZ (2010) Effect of chemical treatments on properties of green coconut fiber. Carbohydr Polym 79(4): 832-838.

51. Abraham E, Deepa B, Pothen LA, Cintil J, Thomas S, et al. (2013) Environmental friendly method for the extraction of coir fibre and isolation of nanofibre. Carbohydr Polym 92(2): 1477-1483.

52. Kacurakova M, Capek P, Sasinkova V, Wellner N, Ebringerova A (2000) FT-IR study of plant cell wall model compounds: pectic polysaccharides and hemicelluloses. Carbohydr Poly 43(2): 195-203.

53. Ferreira LP, Moreira AN, Delazare T, Oliveira GE, Souza FG (2012) Petroleum absorbers based on CNSL, furfural and lignin-the effect of the chemical similarity on the interactions among petroleum and bioresins. Macromol Symp 319(1): 210-221.

54. Tamanini C, Hauly MC, de O (2004) Resíduos agroindustriais para produção biotecnológica de xilitol. Semina Ciênc Agrár 25(4): 315-330.

55. Borges ER (2011) Succinic acid production from sugarcane bagasse hemicellulose hydrolysate by Actinobacillus succinogenes. J Ind Microbiol Biotechnol 38(8): 1001-1011.

56. Wang Y, Song H, Hou JP, Jia CM, Yao S (2013) Systematic isolation and utilization of lignocellulosic components from sugarcane bagasse. Sep Sci Technol 48(14): 2217-2224.

57. Plackett DV, Letchford K, Jackson JK, Burt HM (2014) A review of nanocellulose as a novel vehicle for drug delivery. Nord Pulp Pap Res 29(1): 105-118.

58. Souza FG, Oliveira GE, Anzai T, Richa P, Cosme T, et al. (2009) A sensor for acid concentration based on cellulose paper sheets modified with polyaniline nanoparticles. Macromol Mater Eng 294(11): 739-748.

59. Saralegi A, Gonzalez ML, Valea A, Eceiza A, Corcuera MA (2014) The role of cellulose nanocrystals in the improvement of the shape-memory properties of castor oil-based segmented thermoplastic polyurethanes. Compos Sci Technol 92: 27-33.

60. Buono P, Averous L, Duval A, Habibi Y (2018) Clicking biobased polyphenols: A sustainable platform for aromatic polymeric materials. ChemSusChem, Wiley Online Library, USA.

61. Ramamoorthy SK, Skrifvars M, Persson A (2015) A review of natura fibers used in biocomposites: plant, animal and regenerated cellulose fibers. Polym Rev 55(1): 107-162.

62. Saba N, Tahir PM, Jawaid M (2014) A review on potentiality of nano filler/natural fiber filled polymer hybrid composites. Polymers 6(8) 2247-2273.

63. Célino A, Freour S, Jacquemin F, Casari P (2014) The hygroscopic behavior of plant fibers: a review. Front Chem1: 43.

64. Malenab RAJ, Ngo JPS, Promentilla MAB (2017) Chemical treatment of waste abaca for natural fiber-reinforced geopolymer composite. Materials 10(6): 579.

65. Assaedi H, Shaikh FUA, Low IM (2017) Effect of nanoclay on durability and mechanical properties of flax fabric reinforced geopolymer composites. J Asian Ceram Soc 5(1): 62-70.
66. Kroehong W, Jaturapitakkul C, Pothisiri T, Chindaprasirt P (2018) Effect of oil palm fiber content on the physical and mechanical properties and microstructure of high-calcium fly ash geopolymer paste. Arab J Sci Eng, pp. 1-10.

67. Murri AN, Medri V, Landi E (2017) Production and thermomechanical characterization of wool-geopolymer composites. J Am Ceram Soc 100(7): 2822-2831.

68. Abdollahnejad Z, Mastali M, Luukkonen T, Kinnunen P, Illikainen M (2018) Fiber-reinforced one-part alkali-activated slag/ceramic binders. Ceram Int 44(80): 8963-8976.

69. Bhutta A, Farooq M, Borges PHR, Banthia N (2018) Influence of fiber inclination angle on bond-slip behavior of different alkali-activated composites under dynamic and quasi-static loadings. Cem Concr Res 107: 236-246.

70. Bhutta A, Farooq M, Banthia N (2018) Matrix hybridization using waste fuel ash and slag in alkali-activated composites and its influence on maturity of fiber-matrix bond. J. Clean. Prod 177: 857-867.

71. Cao M, Wang C, Xia R, Chen P, Miao J, et al. (2018) Preparation and performance of the modified high-strength/high-modulus polyvinyl alcohol fiber/polyurethane grouting materials. Constr Build Mater 168: 482-489.

72. Guerin HAL, Elliott DM (2005) The role of fiber-matrix interactions in a nonlinear fiber-reinforced strain energy model of tendon. J Biomech Eng 127(2): 345-350.

73. Pangelinan AB, Mccullough RL, Kelley MJ (1994) Fiber-matrix interactions in thermoplastic composites, fiber-matrix interactions in thermoplastic composites. J Thermoplast Compos Mater 7: 192-207.

74. Hanzhou Y, Yang Z, Zhiming Y, Jun M (2018) Effects of cellulose, hemicellulose, and lignin on the morphology and mechanical properties of metakaolin-based geopolymer. Constr Build Mater 173: 10-16.

75. He P, Jia D, Lin T, Wang M, Zhou Y (2010) Effects of high-temperature heat treatment on the mechanical properties of unidirectional carbon fiber reinforced geopolymer composites. Ceram Int 36(4): 1447-1453.

76. Leite FL, Herrmann PSP, Da Róz AL, Ferreira FC, Curvelo AS, et al. (2006) Investigation of sisal fibers by atomic force microscopy: morphological and adhesive characteristics. J Nanosci Nanotechnol 6(8): 2354-2361.

77. Chen R, Ahmari S, Zhang L (2014) Utilization of sweet sorghum fiber to reinforce fly ash-based geopolymer. J Mater Sci 49(6): 2548-2558.

78. Ars ̃̃"ne MA, Bilba K, Savastano H, Ghavami K (2013) Treatments of nonwood plant fibres used as reinforcement in composite materials. Mater Res 16(4): 903-923.

79. Xiao B, Sun XF, Sun R (2001) Chemical, structural, and thermal characterizations of alkali-soluble lignins and hemicelluloses, and cellulose from maize stems, rye straw, and rice straw. Polym Degrad Stab $74(2): 307-319$

80. Lapierre C, Jouin D, Monties B (1989) On the molecular origin of the alkali solubility of Gramineae lignins. Phytochemistry 28(5): 1401-1403.

81. Ali A, Shaker K, Nawab Y, Jabbar M, Hussain T, et al. (2018) Hydrophobic treatment of natural fibers and their composites-A review, Hydrophobic treatment of natural fibers and their composites-A review. J Ind Text 47(8): 2153-2183.

82. Sepe R, Bollino F, Boccarusso L, Caputo F (2018) Influence of chemical treatments on mechanical properties of hemp fiber reinforced composites. Compos Part B Eng 133: 210-217.

83. Gunti R, Prasad AVR, Gupta AVSSKS (2016) Mechanical and degradation properties of natural fiber-reinforced PLA composites: Jute, sisal, and elephant grass. Polym Compos 39(4): 1125-1136. 
84. Sharma P, Pant S, Rai S, Yadav RB, Sharma S (2017) Green synthesis and characterization of silver nanoparticles by Allium cepa L. to produce silver nano-coated fabric and their antimicrobial evaluation. Appl Organomet Chem 32(3): e4146.

85. Kundu SP, Chakraborty S, Majumder SB, Adhikari B (2018) Effectiveness of the mild alkali and dilute polymer modification in controlling the durability of jute fibre in alkaline cement medium. Constr Build Mater 174: 330-342.

86. Oushabi A, Sair S, Hassani OF, Abboud Y, Tanane O, et al. (2017) The effect of alkali treatment on mechanical, morphological and thermal properties of date palm fibers (DPFs): Study of the interface of DPFPolyurethane composite. South Afr J Chem Eng 23: 116-123.

87. Pereira PHF, Rosa M, Cioffi MOH, Benini KCC, Milanese A, et al. (2015) Vegetal fibers in polymeric composites: a review. Polímeros 25(1): 9-22.

88. Pickering KL, Efendy MGA, Le TM (2016) A review of recent developments in natural fibre composites and their mechanical performance. Compos Part Appl Sci Manuf 83: 98-112.

89. Ray D, Das M, Mitra D (2009) Influence of alkali treatment on creep properties and crystalinity of jute fibres. Bio Resources 4(2): 730-739.

90. Ferreira SR, Silva F, Lima PRL,Toledo F (2017) Effect of hornification on the structure, tensile behavior and fiber matrix bond of sisal, jute and curauá fiber cement based composite systems. Constr Build Mater 139: 551-561.

91. Jo BW, Chakraborty S, Yoon KW (2014) A hypothetical model based on effectiveness of combined alkali and polymer latex modified jute fibre in controlling the setting and hydration behaviour of cement. Constr Build Mater 68: 1-9.

92. Chakraborty S, Kundu SP, Roy A, Adhikari B, Majumder SB (2013) Polymer modified jute fibre as reinforcing agent controlling the physical and mechanical characteristics of cement mortar. Constr Build Mater 49: 214-222.
93. Fidelis MEA, Toledo FRD, Silva F, Mechtcherine V, Butler M, et al. (2016) The effect of accelerated aging on the interface of jute textile reinforced concrete. Cem Concr Compo 74: 7-15.

94. Santos RD, Ferreira SR, Oliveira GE, Silva F, Souza FG, et al. (2017) Impact of alkaline hornification in jute fibers on the tensile strength. MOJ Polym Sci 1(5): 169-172.

95. Korniejenko K, Frączek E, Pytlak E, Adamski M (2016) Mechanical properties of geopolymer composites reinforced with natural fibers. Procedia Eng 151: 388-393.

96. Ranjbar N, Talebian S, Mehrali M, Kuenzel C, Cornelis Metselaar HS, et al. (2016) Mechanisms of interfacial bond in steel and polypropylene fiber reinforced geopolymer composites. Compos Sci Technol 122: 73-81.

97. Ganesan N, Indira PV, Santhakumar A (2014) Influence of steel fibres on tension stiffening and cracking of reinforced geopolymer concrete. Mag Concr Res 66(6): 268-276.

98. Correia EAS, Torres SM, Alexandre de 0, Eliel M, Gomes KC, et al. (2013) Mechanical performance of natural fibers reinforced geopolymer composites. Mater Sci Forum 758: 139-145.

99. Alomayri T, Low IM (2013) Synthesis and characterization of mechanical properties in cotton fiber-reinforced geopolymer composites. J Asian Ceram Soc 1(1): 30-34.

100. Alomayri T, Shaikh FUA, Low IM (2014) Synthesis and mechanical properties of cotton fabric reinforced geopolymer composites. Compos Part B Eng 60: 36-42.

101. Chen R, Ahmari S, Zhang L (2014) Utilization of sweet sorghum fiber to reinforce fly ash-based geopolymer. J Mater Sci 49(6): 2548-2558.

102. Assaedi H, Alomayri T, Shaikh FUA, Low IM (2015) Characterisation of mechanical and thermal properties in flax fabric reinforced geopolymer composites. J Adv Ceram 4(4): 272-281.
Creative Commons Attribution 4.0 International License

For possible submissions Click Here
Submit Article

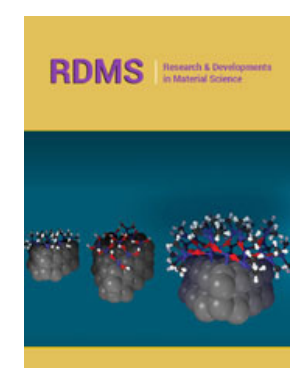

\section{Research \& Development in Material Science}

\section{Benefits of Publishing with us}

- High-level peer review and editorial services

- Freely accessible online immediately upon publication

- Authors retain the copyright to their work

- Licensing it under a Creative Commons license

- Visibility through different online platforms 